\title{
Study on the Sustainable Development of China's Cultural Industry From the Perspective of Culture-Technology Fusion
}

\author{
Zhao Cuicui \\ Baicheng Normal University, Baicheng 137000, China \\ email: 18743607552@163.com
}

Keywords: Culture-Technology, Fusion, Cultural Industry, Sustainable Development

\begin{abstract}
This paper introduces the connotation of the sustainable development of China's cultural industry from the perspective of Culture-Technology fusion, and expounds the impetus for the sustainable development of China's cultural industry from the perspective of Culture-Technology fusion. According to this study, according to the regional coordination of the sustainable development of China's cultural industry from the perspective of Culture-Technology fusion carried out in-depth research and analysis, published some of their suggestions. I hope this research can be a reference and help to the sustainable development of China's cultural industry.
\end{abstract}

\section{Introduction}

With the development of social economy in our country, the cultural industry has the characteristics of high integration and high added value, so it can realize the optimization of industrial structure, and receive more and more attention. Compared with the developed countries, the development of China's cultural industry is still in its early stage, the contribution of the national economy and influence is not very significant, the cultural industry accounted for the proportion of GDP in the whole country is very low. In addition, the internal structure of the cultural industry, the internal structure of the cultural industry of our country is lack of scientific rationality. Although it contains content industry, media and cultural industry platform, manufacturing industry of three parts, but more concentrated in manufacturing culture industry and the media industry. The content and platform of industry the proportion is very low. The cultural industry of our country still has a weak East West and so on, this will further affect China The development of the industry. Therefore, in order to better promote the sustainable development of China's cultural industry, the state must be adjusted according to the industrial structure, make regional before the development of cultural industry coordination. This paper carried out research and analysis.

\section{Connotation of Sustainable Development of China's Cultural Industry from the Perspective of Culture-Technology Integration}

Introduction of Culture-Technology Fusion Perspective. The integration of culture and technology is reflected in many aspects[1]. First of all, on the industry level, the integration of culture and technology industry, mainly refers to the enterprises need to reinforce the current products and technology toward the cultural industry development perspective, to effectively grasp the regional cultural industry development intrinsic demand, find the type of technology and regional cultural industry development the product. Therefore, from the perspective of cultural industries, technology can play a leading role, can greatly promote the progress and development of the cultural industry. Launched mining for the region and the country's cultural industry development, to ensure that the technology is better applied in the actual cultural industry, change the current mode of production culture industry. To promote the transformation of cultural form. Secondly, on the enterprise perspective, the effective integration of culture and technology, mainly refers to the mutual cooperation between different areas and within the same area of different types of enterprises of science and technology and enterprise culture[2]. In this way, the cultural enterprises in product innovation needs to better penetrate into the field of science and technology innovation, and innovation the results of science and technology enterprises to transform cultural 
products. The products and services for corporate culture and innovative mining, strengthen exchanges and cooperation between domestic and foreign enterprises, the effective integration of technology innovation and the internal demand and other aspects can be achieved between enterprise culture and science and technology enterprises[3].Finally, on the resource perspective, culture is a more creative cultural resources. In product innovation, science and technology enterprises need deep mining area and national cultural resources. With the help of technology innovation, the cultural innovation can change from the concept of better practical products and technology, cultural and creative elements there is a very high added value, at the same time it is very difficult to copy. In different countries and different regions, the cultural resources there are very obvious differences. Therefore, in the actual process of product innovation, must do good combination between creative and technical resources, realize the effective transformation of technological innovation knowledge resources. Strengthen technical innovation, put forward more new ideas.

Connotation of Sustainable Development of China's Cultural Industry from the Perspective of Culture-Technology Integration. Sustainable development is not only the need of comprehensive consideration of economic factors, but also need to consider the ecological and social factors[3]. With the improvement of the concept of sustainable development, sustainable development after not only need to meet the needs of people, but also need to meet the needs of future generations. In the connotation of sustainable development, the main it is emphasized that a comprehensive, endogenous and integrative principle, belongs to the natural, social and economic system, is a complex dynamic and open characteristics, there is both a level very obvious. The sustainable development includes the internal response between people and external between man and nature in response.

The cultural resources mainly exists in the form of spiritual connotation, different from the general natural resources. The most obvious characteristics of cultural resources is to achieve repeated and repeated utilization, great value of development. The sustainable development of cultural industry also stressed the protection against cultural resources, development and utilization. The sustainable development is to the soul of the use of cultural resources, in the process of the sustainable development of cultural resources, to adhere to the development degree, coordination degree and sustainability principles, to ensure effective coordination between the three. Mutual coordination and mutual benefit between the three only to do this, the cultural industry can truly become the road of sustainable development[4].

Therefore, the Culture-Technology fusion connotation of sustainable development of China's cultural industry from the perspective mainly contains the following three aspects: First, the sustainable development of cultural industry involves many areas, industries, enterprises, resources, need each other coordination and interaction. Second, the interaction of multiple levels is the power source of the sustainable development of cultural industry, not only there are industry level technology pulling power, including the level of resources and the interaction between the level of corporate culture force. Third, the key to the sustainable development of China's cultural industry is to handle the relationship between the different areas of the cultural industry, combined with the current situation of China's cultural industry, must ensure that the eastern, central, balance the development of the western region.

\section{The Motive Force of Sustainable Development of Chinese Cultural Industry from the Perspective of Culture-Technology Integration}

Pulling Power at Industrial Level. At the present stage of China's cultural industry development in various provinces and cities as the core technology, this kind of phenomenon in the IT industry is particularly obvious[5]. The network technology, information technology and the cultural industry can effectively combine together, to 3D animation, network publishing and other aspects development. Improve the rich cultural content, cultural the content will be better spread. Each enterprise research and development of some new technologies and products to expand the national cultural industry, the cultural industry will help toward more broad direction. Therefore, in the 
industry level, to the leading role in technology development of cultural industry, stimulating the development of the cultural industry, through deep mining for national cultural industry development and regional development of cultural industries, can make mature technology effectively into cultural industry, cultural transformation The mode of industrial production[6].

Cultural Drive at the Enterprise Level. On the corporate level, "culture" more refers to the cultural needs of enterprises in product innovation. If you want to occupy more market share, occupy more advantages in the process of competition, so enterprises need for cultural products and cultural creation, can not simply copy the traditional culture of creative products, technology, effective transformation of ideas. Different cultural products in the process of sustainable development can effectively change the fundamental for the sustainable development of the cultural industry. Cultural enterprises can enhance the cooperation between enterprises and technological exchanges, in-depth research and Analysis on cultural products and service innovation, optimize product form and existing technology, create new cultural products more, the cultural market, promote the sustainable development of culture.

The Interaction of Cultural and Technological at Resources Level. Culture is a more creative cultural resources. In the cultural product innovation, to make effective integration between cultural and creative and professional technology. The creative people find area, city and national cultural resources, gather a good cultural and creative in combination with advanced technology together, realize the effective transformation of intangible cultural creativity, and ultimately promote the sustainable development and utilization of cultural resources. Cultural and creative elements with additional value is very high, and it is hard to achieve replication in different regions of the cultural resources have different difference. On the one hand, the innovation of cultural products, the integration of cultural and creative and technical resources to do, for the culture for the development and utilization of resources, and promote China's sustained and healthy development of cultural industries. On the other hand, by acquiring the heterogeneity of abundant knowledge, change technical knowledge resources Foundation, find more innovative cultural and creative.

\section{Regional Coordination Path of Sustainable Development of Cultural Industry in China from the Perspective of Culture-Technology Integration}

Through the New Technology Products to Activate the Eastern New Culture Industry, Promote the Development of the Central Cultural Industry. The eastern region has a very good development of the cultural industry, the development of earlier, a good development trend. The eastern region is the development of cultural industry, actively explore the new technology, promote the upgrading of traditional cultural industry, to promote the digital technology in TV applications better, the publishing industry and so on. Through high hormone to strengthen the implementation of cultural products performance art, combined with the actual condition of the development of cultural industry in some provinces and cities in eastern region, by leading the new technology, can be a good foundation for the development of cultural industries in the eastern region lay, stimulate new cultural formats[7].

In contrast, in the development of capital investment in China's western region is relatively small, the lack of technological innovation by technology development foundation. In addition the current overall economic impact, such as the development of new network technology development strength is not very strong. In this situation, the cultural industry development of the central region, the eastern region can be introduced the development of a mature cultural products, effective docking to traditional culture and high technology, to develop more products with market value and cultural value, and ultimately promote the progress of the sustainable development of the cultural industry of our country[8].

The path of regional coordinated development in this area is more leading the new technology in the cultural industries. Firstly, the research and development of new technologies and products, and promote the development of traditional industries in the eastern, triggering a series of new cultural industry, to the eastern culture toward the high-end industrial point of development. After the introduction of the eastern region to develop a more mature product and the fusion between 
technology, strengthen the traditional culture of central China and the latest technology, and ultimately promote the progress and development of cultural industries in the central region.

Strengthen Cooperation of Eastern Media and Western Cultural Tourism Enterprises, Promoting the Effective Integration of Media Technology and Tourism Resources. The western region has rich tourism resources, the development of cultural industry is more concentrated in the cultural tourism industry. Because the western area and the media platform for industrial development is relatively slow, new media and the lack of products. In this case, to promote the sustainable development of the resources, it is necessary to use the new media communication technology to promote the development of cultural tourism resources in the western region, the cultural tourism industry has a better development.

There are a lot of new media technology and the Internet in the eastern region of China, and there are many innovative cultural enterprises. The cultural industry of the western region's cultural tourism enterprises must strengthen exchanges and cooperation between enterprises in the eastern regions, according to the network technology improvement, include micro-blog, video and other media content and platform to promote the development of local cultural tourism resources. In addition, the importance of the development of cultural tourism resources in the process, but also the need to improve the technology for docking with the public the importance of regional cultural resources, good culture industry extension, improve the degree of attention in the development of derivative products and cultural aspects of the manufacturing industry.

To Promote the Development of Cultural Content Industry in the East through the Unique Cultural Resources in the Central and Western Regions. To promote the development of cultural industry in the eastern region, enterprises need to have new technology guidance, but also need to have the unique creative process. In cultivating innovative talents in enterprises and universities, need to pay more attention to the cultural resources of the central and western regions of the absorption, R \& D personnel and creative staff to create new ideas, promote the culture industry development. The development of this area are more concentrated in the integration of technology resources and the culture of entrepreneurship, by absorbing western profound and unique cultural resources, can inspire creative people's unique creativity, to better promote the development of cultural industry in the eastern region, and close between the international cultural industry gap.

\section{Conclusion}

The current development of China's cultural industry is still at a low level, there is a certain gap with the developed countries there. To achieve the sustainable development of China's cultural industry, the government should first activate the eastern new cultural industry through new technologies, promote industrial development. The culture of central government to do between the Eastern and Western media cultural tourism enterprises the effective cooperation, promote the integration of media technology and tourism resources. Finally, the government should through the unique cultural resources in central and western regions to promote the development of the eastern cultural content industry. At the same time, with the development of these methods, it can promote the sustainable development of China's cultural industry.

\section{References}

[1] Wang Yongming. Countermeasures for sustainable development of rural leisure cultural industry in the process of urban rural integration -- Taking Suzhou area as an example[J]. Academic Forum,2014,37(1):133-138.

[2] Hu Huilin. The key to the sustainable development of cultural industry -- the theory of harmonious unity between the development of cultural industry and the spiritual relationship among human, society and nature[J].Journal of Zhejiang Party School of C.P.C,2015,31(1):12-18.

[3] Wang Yongming. Logic thinking of sustainable development of rural leisure cultural industry[J]. Journal of the Party School of Guiyang Committee of C.P.C,2014,(6):46-49. 
[4] Yang Ning. Reflections on the sustainable development of Henan folk culture industry[J]. Journal of Zhoukou Normal University,2014,(4):97-100.

[5] Gao Xiaoli. Problems and Countermeasures of sustainable development of Zherong paper cutting culture industry[J].Journal of Ningde Normal University(Philosophy and Social Sciences), 2017, (1):52-55.

[6] Zhao Guodong. The significance and status quo of the sustainable development of cultural industry in Tibet[J].The Theoretical Platform of Tibetan Development,2016,(6):49-52.

[7] Zhang Baiping, Peng Ying. Study on the sustainable development of Guizhou ethnic culture industry[J]. Journal of Anshun University,2015,(5):117-119.

[8] Cheng Yikang. Technological culture -- the cultural education theory of the training of technical applied talents[J]. Journal of Vocational Education,2016,(24):14-19. 